\title{
Laparoscopic Surgery in 3D Improves Results and Surgeon Convenience in Sleeve Gastrectomy for Morbid Obesity
}

Fernando Martinez-Ubieto ( $\sim$ fmubieto@telefonica.net )

Viamed Montecanal Hospital

Ignacio Barranco-Dominguez

Viamed Montecanal Hospital

Lucía Tardós-Ascaso

Department of Anesthesia, Resuscitation and Pain Therapy. Miguel Servet University Hospital.

Zaragoza, Spain.

Teresa Jiménez-Bernadó

Department of Physiatry and Nursing. Faculty of Health Sciences. University of Zaragoza. Zaragoza, Spain

\section{Ana Pascual-Bellosta}

Department of Anesthesia, Resuscitation and Pain Therapy. Miguel Servet University Hospital. Zaragoza, Spain.

\section{Cristian Aragón-Benedí}

Department of Anesthesia, Resuscitation and Pain Therapy. Miguel Servet University Hospital. Zaragoza, Spain.

Jose Manuel Ramírez-Rodriguez

Department of Surgery. Faculty of Medicine. University of Zaragoza. Zaragoza, Spain Javier Martínez-Ubieto

Department of Anesthesia, Resuscitation and Pain Therapy. Miguel Servet University Hospital. Zaragoza, Spain.

\section{Research Article}

Keywords: Laparoscopy, gastric sleeve, vertical gastrectomy, 3D image, bariatric surgery.

Posted Date: April 13th, 2021

DOI: https://doi.org/10.21203/rs.3.rs-399100/v1

License: (a) (1) This work is licensed under a Creative Commons Attribution 4.0 International License. Read Full License 


\section{Abstract}

Background. Advanced laparoscopic procedures are still challenging. One critical issue is the lack of stereoscopic vision. The aim of this surgical study is to evaluate whether 3D vision offers any advantages for surgical performance over 2D vision during sleeve gastrectomy for morbid obesity using a laparoscopic system that allows changing between 2D and 3D optics.

Method. A total of 78 patients were analyzed, with 37 in the 2D group and 41 in the 3D group. Performance time, hospital stay, complications and early outcomes were collected. To assess the quality of the 2D and 3D techniques, visual analog scales (VASs) from 0 to 10 were designed, and image quality, depth of field, precision in performing tasks and general ergonomics were measured.

Results. According to the vision system used, the mean duration of surgery was $85 \pm 16.8$ minutes for patients operated on with the 2D system and $69 \pm 16.9$ minutes for those operated on with the 3D system. There were no significant differences between the overall percentages of complications according to the type of vision used. However, postoperative complications were more severe in the 2D laparoscopy group. The average length of stay was shorter for patients in the 3D group. Regarding the differences perceived by the surgeon, the depth of field and the precision of tasks were better in the 3D vision group.

Conclusion. The 3D system provided greater depth perception and precision in more complex tasks, enabling safer surgery. This led to a reduction in the operative time and hospital stay. Moreover, the severity of complications was less.

\section{Introduction}

Vertical gastrectomy is currently the most widely used technique in the surgical treatment of obesity and its comorbidities. Its relative technical simplicity and the good results published in medium- and longterm studies have made it the technique of choice in many cases. Nevertheless, possible long-term challenges remain, such as new weight gain and the appearance of de novo gastroesophageal reflux ${ }^{[1-}$ 3].

The laparoscopic approach is indicated for this kind of surgery and is usually a two-dimensional approach. However, for some years, the possibility of a three-dimensional approach has come to fruition. Initially, this 3D approach did not gain much popularity since, for most surgeons, undesirable effects such as dizziness, double vision and instability did not outweigh the potential benefits. However, as these systems have improved, many negative effects have become less prevalent and have thus made the advantages that could be obtained from a 3D vision more apparent, particularly the sense of depth when operating. In short, an improvement in the technique was achieved in the sense that surgeons feel more comfortable and safer during surgery, affecting the operating time and the safety of the surgery ${ }^{(4-6)}$. 
Conflicting previous findings on differences between 2D and 3D laparoscopy and the reported lack of studies comparing the use of both methods in bariatric surgery encouraged us to compare various parameters during sleeve gastrectomy, such as image quality, depth of field, precision and performing tasks and general ergonomics, using a visual analogue scale (VAS). A VAS is a response scale that is widely used in questionnaires. For subjective image quality assessments, VAS provides characteristics that cannot be directly measured. The observer indicates the result making a mark over a $10-\mathrm{cm}$ rule. A VAS could be a better option to determine image quality in endoscopy and radiologic studies. In bariatric surgery, VAS has been used frequently to assess postoperative pain and even hunger and satiety $(7,8)$, but until now, VAS has been scarcely described in the comparison of 3D and 2D laparoscopic bariatric surgery. The differences that may occur in the comparison of these two types of images in this bariatric surgical technique in terms of the operative time, hospital stay, complications and postoperative results were assessed in this study using this method with VAS.

\section{Methods}

The prospective data of patients operated on for morbid obesity between July 2013 and March 2015 were collected. The standard 5-trocar tubular gastrectomy or gastric sleeve technique was used, and the surgery was performed by the same surgical team with extensive experience in advanced laparoscopic surgery. Olimpus ${ }^{\circledR}$ equipment with Endoeye optics (ENDOEYE FLEX 3D, Olympus Winter \& IBE GMBH, Hamburg, Germany) was used, which allows the operator to easily change from 2D to 3D vision and vice versa. When in the 3D viewing mode, polarized glasses were used. The technique in all cases consisted of gastric section from $4 \mathrm{~cm}$ of the pylorus to the angle of His on a $42 \mathrm{~F}$ bougie with Echelon Endoflex ${ }^{\circledR}$ of green, golden or blue loads depending on the thickness of the stomach and at the discretion of the surgeon. The section was oversewn with Surgipro ${ }^{\circledR} 2 / 0$ in three seroserosal running sutures. A leak test was performed with methylene blue, and a Jackson-Pratt aspiration drain was left.

The variables collected included 3 main periods: preoperative, intraoperative, and postoperative. The following formulas were used to measure excess weight loss (EWL): Devine's formula in men (PI $=50+$ $0.91 \times$ (height in $\mathrm{cm}-152.4)$ ) and Robinson's formula in women ( $\mathrm{PI}=45.5+0.91 \times$ (height in $\mathrm{cm}$ 152.4)). The severity of postoperative complications was analyzed according to the Clavien-Dindo classification ${ }^{[9]}$.

Preoperative comorbidities such as smoking, antiplatelet and anticoagulant intake, history of previous abdominal surgery, heart disease, hypertension, obstructive sleep apnea syndrome (OSA) and the use of nocturnal CPAP devices, diabetes, arthropathy, and dyslipidemia were recorded and studied.

Due to the ease of changing vision between 3D and 2D by pressing a button on the camera head, we found it very easy to assess the parameters studied, so intraoperative quality visions can be immediately compared to be able to score them properly. To evaluate the quality of the $2 \mathrm{D}$ and $3 \mathrm{D}$ techniques, visual analog scales (VASs) from 0 to 10 were designed, and image quality, depth of field, precision in 
performing tasks and general ergonomics were measured. We considered for these items 10 as the best definition and 0 as the worst, with 5 being the parameter intermediate.

Postoperative data collection was performed prospectively from the day of surgery until the last review in outpatient consultations, and the data were entered into an Excel ${ }^{\circledR}$ database (Microsoft Corp., Redmond, WA, USA). There were no patients lost to follow-up, and only 2 patients changed their place of residence, whose evaluation was completed by telephone. For statistical analysis, univariate analysis was performed, and the data are expressed as the means \pm standard deviation (SD) or numbers and percentages of patients. For hypothesis testing, in the case of quantitative versus qualitative variables, ANOVA tests for parametric data and Kruskal-Wallis tests for nonparametric data were used. For the comparison of qualitative variables, the $\mathrm{X} 2$ independence test was used. Finally, the Spearman correlation was used as a correlation test. The free software program $\mathrm{R}$ was used for statistical analysis.

Informed consent was obtained from all patients, and the study was approved by the hospital ethics committee (Viamed Montecanal ethics committee). This study followed the principles of the Declaration of Helsinki by the World Medical Association.

\section{Results}

Seventy-eight vertical gastrectomies were performed, 37 using conventional 2D laparoscopy and 41 using the same technique with the 3D vision system.

The distribution by sex was 46 women (59\% of the total) and 32 men (41\%) and was similar in both groups. The mean age was $42.3 \pm 12.6$ years (mean \pm SD), with a range between 15 and 70 years, and the age distributions within the groups were very similar. The mean height of the patients was $167 \pm 8.34 \mathrm{~cm}$. The initial mean weight of the patients preoperatively was $121 \mathrm{~kg}$ in the overall series, ranging from 86 to $185 \mathrm{~kg}$ with an SD of $20.4 \mathrm{~kg}$. The mean weight in the 2D group was $118.9 \pm 19.9 \mathrm{~kg}$, and that in the 3D group was $122.2 \pm 21.7 \mathrm{~kg}$. Both distributions were similar in both groups $(p=0.47>0.05)$. The mean initial BMI of the series was $42.9 \pm 6.33 \mathrm{~kg} / \mathrm{m} 2$, and more than $75 \%$ of the patients had a BMl $>39 \mathrm{~kg} / \mathrm{m} 2$. No significant differences were found in the mean BMI of the groups according to the type of vision used $(p=0.0503>0.05)($ Table 1$)$. 
Table 1

Patient Characteristics

\begin{tabular}{|llll|}
\hline & 2D(37 patients) & $3 D(41$ patients $)$ & $P$ \\
\hline Age (years) & $42.6 \pm 11.6(19-67)$ & $42.1 \pm 13.7(15-70)$ & $>0.05$ \\
\hline Gender & 24 female/13 male & 22 female/ 19 male & $>0.05$ \\
\hline Body weight $(\mathrm{kg})$ & $118.9 \pm 19.1$ & $122.2 \pm 21.7$ & 0.47 \\
\hline BMI (kg/m $\left.{ }^{2}\right)$ & $43($ range $35-62)$ & $42($ range $31-58)$ & 0.0503 \\
Hypertension & $13(35.1 \%)$ & $12(29.3 \%)$ & $>0.05$ \\
Diabetes & $13(35.1 \%)$ & $13(31.7 \%)$ & $>0.05$ \\
\hline Sleep apnea & $14(37.8 \%)$ & $9(22 \%)$ & $>0.05$ \\
\hline Smokers & $16(43 \%)$ & $19(46 \%)$ & $>0.05$ \\
\hline
\end{tabular}

In the intraoperative period, the duration of the intervention was $76 \pm 18.6$ minutes, with a range between 45 and 120 minutes. According to the vision system used, the mean duration of the patients operated on with the 2D system was $85 \pm 16.8$ minutes, and that of those operated on with the 3D system was $69 \pm$ 16.9 minutes, a difference that was statistically significant $(p=0,0001<0.05)($ Table 2$)$.

Table 2

Perioperative outcome

\begin{tabular}{|llll|}
\hline & 2D (37 patients) & $3 D$ (41 patients) & $P$ \\
\hline Operating time (minutes) & $85 \pm 16.8$ & $69 \pm 16.9$ & 0.0001 \\
\hline Depth of field (VAS) & 6.89 & 8.97 & $0<0.05$ \\
\hline Precision tasks (VAS) & 6.94 & 8.97 & $0<0.05$ \\
\hline Hospital stay (days) & $2.59 \pm 0.64$ & $2.15 \pm 0.65$ & 0.0041 \\
\hline
\end{tabular}

Regarding the differences perceived by the surgeon, the depth of field in the $2 \mathrm{D}$ vision group obtained an average of 6.89 points on the visual analog scale, while in the 3D vision group, it was 8.97 points. In the precision of tasks, the average points obtained were 6.94 in the $2 \mathrm{D}$ group and 8.97 in the 3D group. In both cases, these differences were statistically significant (Table 2).

During the postoperative period, a total of 10 patients (12.8\%) suffered complications, $13 \%$ of patients in the $2 \mathrm{D}$ group and $12 \%$ in the $3 \mathrm{D}$ group. In total, there were 14 complications in 10 patients, the most frequent being fistula in the staple line (4 cases in total, $5.13 \%$ of the series, three of which required reoperation), atelectasis during the postoperative period (4 cases in total, $5.13 \%$ of the series), and sleeve stenosis ( 3 cases in total). There were no significant differences between the overall percentage of 
complications according to the type of vision used. However, according to the Clavien-Dindo scale, postoperative complications were more severe in the $2 D$ laparoscopy group $(p=0,0001<0,05)$.

The average length of stay was used to compare hospital stays. The mean time was 2.59 days in the 2D group and 2.15 days $(95 \% \mathrm{Cl})$ in the 3D group, with the difference being statistically significant and with almost half a day less in the 3D group $(-0,44$ days, $p=0.0041<0.05)$. No statistically significant differences were found in readmission rates (Table 2).

When studying the behavior related to comorbidities after bariatric surgery, we observed improvements in most of them. Approximately $50 \%$ of the operated patients stopped taking antihypertensive medication. In the case of arthropathy and OSA and the use of CPAP, both experienced significant postoperative improvements.

Excess weight loss (EWL) at 12 months was very similar in both groups, with $68 \pm 18.4 \%$ in the $2 \mathrm{D}$ vision group and $67 \pm 12.8 \%$ in the 3D group, with a nonsignificant difference $(p=0.66>0.05)$. The same occurred at 24 months, with an EWL of $72.3 \pm 18.5 \%$ in the 2D group and $71.7 \pm 18.2 \%$ in the $3 \mathrm{D}$ group, with no statistically significant differences $(p=0.93>0.05)$. Both systems led to similar weight losses in patients after surgery.

\section{Discussion}

In this study, all patients were operated on by the same surgeon (FMU) and by the same surgical technique, which reduces possible biases derived from the analysis of data obtained with different surgical teams or techniques.

A particularity of this study was the use of VASs to measure image quality, depth of field, precision in performing tasks and general ergonomics, since there are no clearly established measurement tools for these parameters in the literature, although there are studies such as the one by Currò et al that used similar questionnaires ${ }^{[11]}$ or subjective surveys. Other studies, such as those by Wilhelm et al. ${ }^{[1]}$ and Smith et al. ${ }^{[12]}$, both published in 2014, used the validated National Aeronautics and Space Administration Task Load Index (NASA-TLI) workload scale, although the evaluation of the rest of the parameters was carried out with subjective questionnaires. The systematic review carried out in 2017 by the group of Fergo et al. ${ }^{[13]}$ also shows that most of the analyzed studies use subjective parameters.

Regarding the average duration of the surgical intervention, many studies coincide in a reduction of the

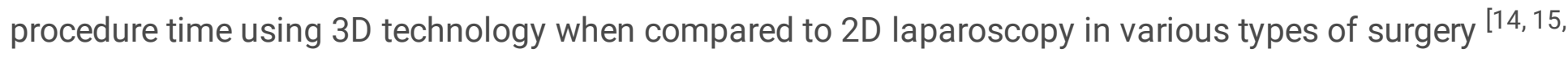
16]. In the study carried out by Padin in 2017, the surgical times were analyzed specifically in bariatric surgery and were 100.22 \pm 41.22 minutes in the 3D group and 124.7 \pm 51.97 minutes in the 2D group, with a statistically significant difference ${ }^{[16]}$. In the present study, the times were shorter, with $69 \pm 16.9$ minutes in the 3D group and $85 \pm 16.8$ minutes in the $2 \mathrm{D}$ group. Most studies find significant differences 
between the 2D and 3D techniques, especially in regard to carrying out more complex tasks such as laparoscopic suturing ${ }^{[11,12,14]}$.

There is consensus that the results obtained by bariatric surgery in the correction of comorbidities are much better than those obtained by other medical means, as described by Colquitt et al. in a systematic review of the Cochrane Database of Systematic Reviews in 2014 [ $\left.{ }^{4}\right]$. Here, a clear improvement in the patient's comorbidities was observed; practically all of them disappeared (arthropathy, OSA, use of CPAP), while the rest improved significantly (HT, DM), which coincides with that reported in other studies [ $\left.{ }^{17}, 18\right]$. In the specific case of hypertension, in this series, approximately $50 \%$ of the operated patients stopped taking antihypertensive medication, coinciding with what was published by Sarkhosh et al in 2012 in a systematic review, where they found an improvement in hypertension in $75 \%$ of patients, achieving complete resolution and the cessation of antihypertensive medication in $58 \%$ of cases ${ }^{[20]}$.

The incidence of postoperative complications was $12.8 \%$, in line with the systematic review of the Cochrane Database of Systematic Reviews published by Colquitt et al. in $2014{ }^{[4]}$, where for any type of bariatric surgery, it ranged from 0 to $37 \%$. In this study, mortality was $0 \%$.

When comparing the 3D and 2D laparoscopy techniques, multiple studies have compared the depth of field perceived by the surgeon as well as the precision in performing more complex tasks, and the vast majority of the literature favors 3D technology, both in an experimental setting ${ }^{[21,22]}$ and in human surgery $[5,12,14]$. Some studies have shown a reduction in the number of errors made using 3D laparoscopes compared to classic 2D laparoscopes $\left({ }^{13,16}\right)$.

When measuring the general ergonomics of laparoscopic surgery with 2D and 3D systems, as previously stated in this discussion, measurement tools are disparate, and subjective evaluations have been used on many occasions. Despite this, most studies find that results in surgeon comfort and adverse effects such as dizziness and headache are the same or improve with 3D systems. When asked about the preference of $2 D$ over 3D, most studies show that experienced and novice surgeons favor $3 D$ surgery $[5,10,13,16,21]$. Furthermore, some of these studies have shown a reduced learning curve with 3D laparoscopy systems compared to classic 2D $[10,16,22]$.

Currently, there is extensive literature comparing 2D and 3D laparoscopic surgery in various types of interventions. Initially, in the late 1990s, some studies were published that did not show significant differences between the 2D and 3D vision systems, which in addition to not showing significant advantages of 3D systems, found a greater number of adverse effects on the surgeon $(23,24,25)$. However, as vision systems have improved, most of the more recent studies comparing these two technologies conclude in favor of the 3D technique for all of the above. In general surgery, studies on laparoscopic cholecystectomy $(25,26)$, laparoscopic surgery for colon cancer ${ }^{[27,28]}$, and laparoscopic duodenopancreatectomy ${ }^{[29]}$, as well as previous studies on gastric cancer ${ }^{[30,31,32]}$ and laparoscopic liver resection ${ }^{[33]}$ reported improvements in surgical time and complications with 3D laparoscopy. The same 
is true in other fields, such as gynecology ${ }^{[34]}$, pediatric surgery ${ }^{[35]}$, and urology ${ }^{[36]}$. However, there are also studies that did not find these differences and established that 3D laparoscopic surgery does not represent advantages over 2D laparoscopic surgery $[37,38]$.

In 2018, the European Association of Endoscopic Surgery (EAES) published a series of agreed recommendations about 3D surgery. It was confirmed that the surgical time is reduced, as well as the complications, obtaining better results in more complex procedures and making fewer mistakes, although they recommend conducting more studies ${ }^{[39]}$.

Finally, there are few studies in the literature comparing 2D and 3D laparoscopy in bariatric surgery. Such studies are mainly those carried out by Currò et al in $2015^{[8]}$, Martínez-Ubieto et al in $2015^{[5]}$ and Padin in $2017^{[14]}$, which arrived at similar conclusions to those of the present study.

In conclusion, adding the results of this study with the reviewed literature, the advantages of 3D vision systems are clear, especially regarding the reduction in surgical time, especially in more complex tasks, and in the commission of fewer errors, enabling safer surgery. The hospital stay was also shorter in those operated on with the 3D technique.

\section{Declarations}

\section{Disclosures:}

Drs F. Martínez-Ubieto, Ignacio Barranco-Dominguez, Lucía Tardós-Ascaso, Teresa Jiménez-Bernadó, Ana Pascual-Bellosta, Cristian Aragón-Benedí, José Manuel Ramírez-Rodríguez and Javier Martínez-Ubieto have no conflict of interest or financial ties to disclose.

\section{References}

1. Pi-Sunyer FX (1993) Medical hazards of obesity. Ann Intern Med 119:655-60

2. WHO (2020). Fact sheets. Available at: https://www.who.int/es/news-room/factsheets/detail/obesity-and-overweight

3. Haslam DW, James WPT (2005) Obesity. Lancet 366:1197-209

4. Colquitt JL, Pickett K, Loveman E, Frampton GK (2014) Surgery for weight loss in adults. Cochrane Database Syst Rev 8:CD003641

5. Martínez-Ubieto F, Jiménez-Bernadó T, Martínez-Ubieto J, Cabrerizo A, Pascual-Bellosta A, MuñozRodriguez L, Jiménez-Bernadó (2015) Three-dimensional laparoscopic sleeve gastrectomy: Improved patient safety and surgeon convenience. Int Surg 100:1134-7

6. Sørensen SMD, Savran MM, Konge L, Bjerrum F (2016) Three-dimensional versus two-dimensional vision in laparoscopy: a systematic review. Surg Endosc 30:11-23 
7. Torquati A, Shantavasinkul PC, Omotosho P, Corsino L, Spagnoli A (2019) Perioperative changes in prouroguanylin hormone response in severely obese subjects after bariatric surgery. Surgery 166 : 456-459

8. Vieira FT, Faria SLCM, Dutra ES, Ito MK, Reis CEG, da Costa THM, de Carvalho KMB (2019) Perception of Hunger/Satiety and Nutrient Intake in Women Who Regain Weight in the Postoperative Period After Bariatric Surgery. Obes Surg 29:958-963

9. Clavien PA, Sanabria JR, Strasberg SM (1992)Proposed classification of complications of surgery with examples of utility in cholecystectomy. Surgery 111:518-26

10. Currò G, La Malfa G, Caizzone A, Rampulla V, Navarra G (2015)Three-Dimensional (3D) Versus TwoDimensional (2D) Laparoscopic Bariatric Surgery: a Single-Surgeon Prospective Randomized Comparative Study. Obes Surg 25:2120-4

11. Wilhelm D, Reiser S, Kohn N, Witte M, Leiner U, Mühlbach L, Ruschin D, Reiner W, Feussner H (2014) Comparative evaluation of HD 2D/3D laparoscopic monitors and benchmarking to a theoretically ideal 3D pseudodisplay: even well-experienced laparoscopists perform better with 3D. Surg Endosc 28:2387-97

12. Smith R, Schwab K, Day A, Rockall T, Ballard K, Bailey M, Jourdan I (2014) Effect of passive polarizing three-dimensional displays on surgical performance for experienced laparoscopic surgeons. Br J Surg 101:1453-9

13. Fergo C, Burcharth J, Pommergaard H-C, Kildebro N, Rosenberg J (2017) Three-dimensional laparoscopy vs 2-dimensional laparoscopy with high-definition technology for abdominal surgery: a systematic review. Am J Surg 213:159-70

14. Wagner OJ, Hagen M, Kurmann A, Horgan S, Candinas D, Vorburger SA (2012) Three-dimensional vision enhances task performance independently of the surgical method. Surg Endosc 26:2961-8

15. Sahu D, Mathew MJ, Reddy PK (2014)3D laparoscopy - Help or hype; initial experience of a tertiary health centre. J Clin Diagnostic Res 8:NC01-3

16. Padin EM, Santos RS, Fernández SG, Jimenez AB, Fernández SE, Dacosta EC, Duran AR, Rial MA, Sanchez ID (2017) Impact of Three-Dimensional Laparoscopy in a Bariatric Surgery Program: Influence in the Learning Curve. Obes Surg 27:2552-6.

17. Grant MC, Yang D, Wu CL, Makary MA, Wick EC (2017) Impact of enhanced recovery after surgery and fast track surgery pathways on healthcare-associated infections: Results from a systematic review and meta-analysis. Ann Surg 265:68-79

18. Ocón Bretón J, Pérez Naranjo S, Gimeno Laborda S, Benito Ruesca P, García Hernández R (2005) Eficacia y complicaciones de la cirugía bariátrica en el tratamiento de la obesidad mórbida. Nutr Hosp 20:409-14

19. Buchwald H, Avidor Y, Braunwald E, Jensen MD, Pories W, Fahrbach K, Schoelles K (2004) Bariatric surgery: A systematic review and meta-analysis. JAMA 292:1724-37

20. Sarkhosh K, Birch DW, Shi X, Gill RS, Karmali S (2012) The Impact of Sleeve Gastrectomy on Hypertension: A Systematic Review. Obes Surg 22:832-7 
21. Tanagho YS, Andriole GL, Paradis AG, Madison KM, Sandhu GS, Varela JE, Benway BM (2012) 2D Versus 3D Visualization: Impact on Laparoscopic Proficiency Using the Fundamentals of Laparoscopic Surgery Skill Set. J Laparoendosc Adv Surg Tech 22:865-70

22. Feng X, Morandi A, Boehne M, Imvised T, Ure BM, Kuebler JF, Lacher M (2015) 3-Dimensional (3D) laparoscopy improves operating time in small spaces without impact on hemodynamics and psychomental stress parameters of the surgeon. Surg Endosc 29:1231-9

23. Zundel S, Lehnick D, Heyne-Pietschmann M, Trück M, Szavay P (2019) A Suggestion on How to Compare 2D and 3D Laparoscopy: A Qualitative Analysis of the Literature and Randomized Pilot Study. J Laparoendosc Adv Surg Tech 29:114-20

24. Chan AC, Chung SC, Yim AP, Lau JY, Ng EK, Li AK (1997) Comparison of two-dimensional vs threedimensional camera systems in laparoscopic surgery. Surg Endosc 11:438-40

25. Hanna GB, Shimi SM, Cuschieri A (1998) Randomised study of influence of two-dimensional versus three-dimensional imaging on performance of laparoscopic cholecystectomy. Lancet 351:248-51

26. Mueller MD, Camartin C, Dreher E, Hänggi W (1999) Three-dimensional laparoscopy. Gadget or progress? A randomized trial on the efficacy of three-dimensional laparoscopy. Surg Endosc 13:46972

27. Su H, Jin W, Wang P, Bao M, Wang X, Zhao C, Wang X, Zhou Z, Zhou H (2019) Comparing short-time outcomes of three-dimensional and two-dimensional totally laparoscopic surgery for colon cancer using overlapped delta-shaped anastomosis. Onco Targets Ther 12:669-75

28. Yoon J, Kang S II, Kim MH, Kim MJ, Oh H-K, Kim D-W, Kang SB (2019) Comparison of Short-Term Outcomes Between 3D and 2D Imaging Laparoscopic Colectomy with D3 Lymphadenectomy for Colon Cancer. J Laparoendosc Adv Surg Tech 29:340-5

29. Xu X, Zheng C, Zhao Y, Chen W, Huang Y (2018)Enhanced recovery after surgery for pancreaticoduodenectomy: Review of current evidence and trends. Int J Surg 50:79-86

30. Liu Z-Y, Chen Q-Y, Zhong Q, Xie J-W, Wang J-B, Lin J-X, Lu J, Cao LL, Li M, Tu RH, Huang ZN, Lin JL, Zheng HL, Zheng CH, Huang CM, Li P (2019) Is three-dimensional laparoscopic spleen preserving splenic hilar lymphadenectomy for gastric cancer better than that of two-dimensional? Analysis of a prospective clinical research study. Surg Endosc 33:3425-35

31. Kanaji S, Suzuki S, Harada H, Nishi M, Yamamoto M, Matsuda T, Oshikiri T, Nakamura T, Fujino Y, Tominaga M, Kakeji Y (2017) Comparison of two- and three-dimensional display for performance of laparoscopic total gastrectomy for gastric cancer. Langenbeck's Arch Surg 402:493-500

32. Chen H, Yu J, Huang Z, Lin X (2014) Application of three-dimensional high-definition laparoscope in laparoscopic radical resection of gastric cancer. Nan Fang Yi Ke Da Xue Xue Bao 34:588-90

33. Velayutham V, Fuks D, Nomi T, Kawaguchi Y, Gayet B (2016) 3D visualization reduces operating time when compared to high-definition 2D in laparoscopic liver resection: a case-matched study. Surg Endosc 30:147-53 
34. Zhao D, Li PP, Wang YT, Shu T, Li B (2019) Comparative study of three-dimensional versus twodimensional laparoscopic $\mathrm{C} 1$ radical hysterectomy for cervical cancer]. Zhonghua Fu Chan Ke Za Zhi 54:173-8

35. Wang Y, Chen W, Xia S, Wang T, Wang S, Zhang F, Li B (2019) Three-Dimensional Versus TwoDimensional Laparoscopic-Assisted Transanal Pull-Through for Hirschsprung's Disease in Children: Preliminary Results of a Prospective Cohort Study in a Tertiary Hospital. J Laparoendosc Adv Surg Tech 29:557-63

36. Aykan S, Temiz MZ, Duymaz T, Ural IH, Colakerol A, Muslumanoglu AY, Semercioz A (2019) Effects of the Three-Dimensional Vision System on Surgical Performance, Muscular Fatigue, and Pain During Urologic Laparoscopic Tasks: Results of Objective Assessments and a Mini Questionnaire Survey. J Laparoendosc Adv Surg Tech 29:346-52.

37. Ajao MO, Larsen CR, Manoucheri E, Goggins ER, Rask MT, Cox MKB, Mushinski A, gu X, Cohen SL, Rudnicki M, Einarsson JI (2019) Two-dimensional (2D) versus three-dimensional (3D) laparoscopy for vaginal cuff closure by surgeons-in-training: a randomized controlled trial. Surg Endosc 34:123743

38. Koppatz H, Harju J, Sirén J, Mentula P, Scheinin T, Sallinen V (2019) Three-dimensional versus twodimensional high-definition laparoscopy in cholecystectomy: a prospective randomized controlled study. Surg Endosc 33:3725-31

39. Arezzo A, Vettoretto N, Francis NK, Bonino MA, Curtis NJ, Amparore D, Arolfo S, Barbeiro M, Boni L, Brodie R, Bouvy N, Cassinotti E, Carus T, Checcuci E, Custers P, Diana M, Jansen M, Jaspers J, Marom G, Momose K, Müller-Stich BP, Nakajima K, Nickel F, Perretta S, Porpiglia F, Sanchez-Margallo F, Sanchez-Margallo JA, Schijuen M, Silecchia G, Passera R, Mintz Y (2019) The use of 3D laparoscopic imaging systems in surgery: EAES consensus development conference 2018. Surg Endosc 33:3251-74 